\title{
Perioperative pain management for thoracic surgery: a narrative review of the literature
}

\author{
Ariane Clairoux, Rami Issa, Marie-Ève Bélanger, Robert Urbanowicz, Philippe Richebé, Véronique Brulotte \\ Department of Anesthesiology And Pain Medicine, Maisonneuve-Rosemont Hospital, CIUSSS de l'Est-de-l'Ile-de-Montreal, University of \\ Montreal, Montreal, Canada \\ Contributions: (I) Conception and design: All authors; (II) Administrative support: None; (III) Provision of study materials or patients: None; (IV) \\ Collection and assembly of data: None; (V) Data analysis and interpretation: None; (VI) Manuscript writing: All authors; (VII) Final approval of \\ manuscript: All authors. \\ Correspondence to: Dre Véronique Brulotte, MD, MSc. Maisonneuve-Rosemont Hospital, CEMTL, University of Montreal School of Medicine, \\ 5415, Boulevard De L'Assomption, Montréal, (Québec), H1T 2M4, Canada. Email: veronique.brulotte@umontreal.ca.
}

Objective: The objective of this article was to review the evidence regarding multimodal analgesia drugs and regional block techniques in the context of thoracic surgery, with a special focus on video-assisted thoracic surgery (VATS).

Background: Despite advances in surgical technique and the increased use of minimally invasive surgery, postoperative pain after thoracic surgery is still significant, especially in the first two postoperative days. Inadequate pain control leads to a reduced rate of pulmonary recovery which can lead to atelectasis, hypoxemia and pneumonia and is significantly linked to an increased incidence of chronic postsurgical pain. However, the optimal analgesic protocol that allows adequate postoperative pain control and facilitates fast recovery of this population has yet to be determined.

Methods: An extensive review of articles published between January 1980 and November 2020 using different combinations of search terms that were relevant to the topic was conducted using PubMed search engine. All published full articles randomised controlled trials comparing the analgesic efficacy of a regional block or of a multimodal analgesic drug to a placebo in patients undergoing either thoracotomy or VATS were included in this review.

Conclusions: Analgesic protocols in thoracic surgery must take into consideration the surgery that is being performed (VATS or thoracotomy) as well as patient's characteristics. Regional blocks are highly effective at providing good postoperative pain control although their duration is limited. Various non opioid analgesic drugs have been evaluated in order to address the various pain generators that cause postoperative pain after thoracic surgery, although none has become a clinical standard. Using a combined multimodal and regional analgesic protocol could improve postoperative pain control and decrease the use of parenteral opioids and their unwanted side effects. Recommendations on multimodal analgesic protocols are given based on the literature.

Keywords: Acute and chronic pain; thoracic surgery; pain management

Received: 31 December 2020; Accepted: 28 September 2021.

doi: $10.21037 /$ ccts-20-184

View this article at: https://dx.doi.org/10.21037/ccts-20-184 


\section{Introduction}

Postoperative pain experienced after thoracic surgery can be severe and typically originates from surgical incisions, damage to lung tissue and ribs, irritation of the pleura and intercostal nerves by the chest tube, and from ipsilateral shoulder pain (ISP) syndrome (1). Postoperative pain after video-assisted thoracic surgery (VATS) is often less pronounced as tissue trauma is less extensive in comparison to thoracotomy, however, can present as severe in some patients, especially during the first $24 \mathrm{~h}(2,3)$.

Inadequate analgesia following thoracotomy or VATS is directly correlated with a reduced rate of recovery of pulmonary function after surgery, which can also lead to atelectasis, hypoxemia and pneumonia as a result of ineffective cough and poor clearance of sputum (3). Moreover, thoracic surgery is associated with a high incidence of chronic postsurgical pain (CPSP), defined by The International Association for the Study of Pain as pain that develops or increases in intensity after a surgical procedure and persists beyond 3 months after surgery (4). Unfortunately, 25-60\% of patients report experiencing CPSP after thoracic surgery (thoracotomy and VATS), which has shown to contribute to emotional suffering, disability, poor quality of life, and increased health costs $(2,5-7)$. The pain is described as being mixed, with both a somatic and neuropathic component $(4,8)$. The exact mechanisms underlying CPSP after thoracic surgery are unknown and have not been extensively studied, although, many risk factors have been identified in the literature. Surgery-related factors can include duration of surgery, trauma to intercostal nerve, and open thoracotomy versus VATS. Thoracotomy is reported as having the highest incidence of CPSP and disability. However, the rate of chronic postoperative pain 6 months after thoracotomy is not significantly different from that reported after VATS $(2,9)$. Patient-related factors include preoperative pain, opioid use, and a catastrophizing tendency, although increased acute pain after surgery is consistently found as the most significant risk factor for CPSP $(2,10)$. Therefore, prevention of CPSP begins with an early and aggressive analgesic treatment plan that significantly reduces acute postoperative pain.

The optimal analgesic protocol after thoracic surgery has not been defined, however must take into consideration both the surgery being performed (VATS $v s$. thoracotomy) and patient's characteristics (pulmonary function, chronic pain, comorbidities). Given the various generators of pain after thoracic surgery, a standardized analgesic strategy that combines multimodal to regional analgesia, while aiming at reducing parenteral opioids, would be necessary to provide proper postoperative analgesia, adequate recovery of lung function, and reduced rate of persistent pain $(2,3,6,11,12)$.

The objective of this narrative review will be to present the available evidence regarding the use of regional blocks for postoperative analgesia after thoracotomy and VATS, followed by a review of the multimodal analgesic strategies that were evaluated in this surgical population. Treatment options for ISP will also be briefly touched on. Finally, recommendations on analgesic strategies will be proposed based on the literature and the authors' experience.

\section{Methods}

This narrative review is presented in accordance with the guidelines for Narrative Review reporting checklist listed by the Equator Network (available at https://dx.doi. org/10.21037/ccts-20-184). We searched PubMed for articles published between January 1980 and November 2020 using different combinations of search terms that were relevant to the topic. All published full articles randomised controlled trials comparing the analgesic efficacy of a regional block or of a multimodal analgesic drug to a placebo in patients undergoing either thoracotomy or VATS were considered for inclusion. Only articles published in English language were included.

\section{Discussion}

\section{Part 1: regional analgesia}

Cutaneous innervation of the thorax, relevant to thoracic surgery, is provided primarily by the intercostal nerves T3-T8 and the phrenic nerve (1) (Figure 1). Two principal cutaneous nerves, the lateral and anterior cutaneous nerves, provide sensory innervation to the lateral and anterior skin of the thorax, respectively. Additionally, the supraclavicular nerve provides cutaneous innervation to the uppermost parts of the thorax. Many types of nerve blocks targeting these nerves have been evaluated in thoracic surgery, the most common being thoracic epidural analgesia (TEA), paravertebral (PVB) and intercostal nerve (ICNB) blocks, and the newer plane blocks: erector spinae plane (ESP) and serratus anterior plane (SAP) blocks. This section will review regional analgesic techniques for thoracotomy and VATS separately. 


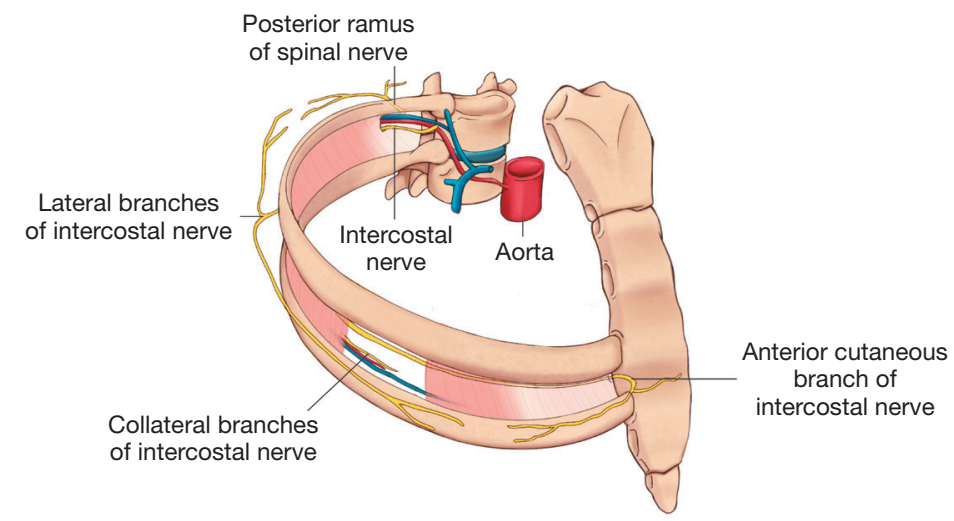

Figure 1 Sensory innervation of the thorax.

\section{Thoracotomy}

Postoperative pain after thoracotomy is reported as one of the most severe types of pain following surgery. Continuous regional analgesia has been reported to significantly improve pain relief after thoracotomy, compared to systemic analgesia $(13,14)$. As such, continuous regional analgesia should be strongly considered for patients after thoracotomy, provided there are no contraindications. TEA is the regional analgesia technique widely regarded as the gold standard for analgesia and reduction of postoperative complications after thoracotomy (15). The most effective preventative strategy to reduce intraand postoperative acute pain, and risks associated to the development of chronic pain after thoracotomy, is to begin the epidural infusion as soon as the catheter is placed and to continuously infuse local anesthetics intra- and postoperatively (16). This also decreases intraoperative need of opioids, which may contribute to significant increases in intraoperative central pain sensitization if administered in high doses (6). However, TEA has the potential to cause significant complications like spinal hematoma and can cause significant sympatholysis, which can lead to hypotension. Alternatively, a continuous PVB can be used, providing comparable analgesia with potentially fewer side effects (17).

\section{VATS}

Optimal postoperative thoracic analgesia after VATS remains an open issue.

Epidurals have been used for VATS surgery. However, the lesser surgical trauma and less intense postoperative pain compared to thoracotomy, the potential for significant side effects associated with thoracic epidural catheterization and the availability of effective, simpler regional analgesia blocks make the use of epidural analgesia questionable in this context (18-20). However, epidural placement may be considered when there is a high probability of conversion to open thoracotomy.

The ICNB is an appealing technique because it is easy to perform. Its primary flaw is a limited duration of action due to unreliable local anesthetic spread. The placement of a catheter could potentially overcome this limitation, however, multiple catheters would be necessary to provide adequate long-acting analgesia (21).

The PVB provides ipsilateral somatic and sympathetic coverage of the hemithorax. PVBs are achieved through blocking the spinal nerves directly after leaving the spinal cord, although there may be intercostal and epidural spread (22). These blocks can be performed either as a "single shot" or continuous injection through a catheter placed percutaneously using ultrasound by the anesthesiologist or visually by the surgeon during surgery. Complications such as vascular puncture, pleural puncture, and pneumothorax are very uncommon with the use of ultrasound guidance (23). Dermatomal spread is variable and multiple injections would theoretically be needed to cover the entire surgical area (22), although sufficient postoperative analgesia at rest, and at movement, is reported using a single paravertebral catheter inserted at the T5 paravertebral space (24).

For many reasons, the newer plane blocks like the ESP and SAP blocks have gained a lot of popularity. First, they are easy to perform, and a single injection provides longer analgesia than most traditional blocks because of poor vascular uptake. Second, unlike the other traditional blocks (intercostal and paravertebral), they are performed far from 
critical structures between two fascial planes, making them safer even in the presence of anticoagulation. Also, they are not associated with any side effects, like hypotension. The SAP block targets the lateral cutaneous branches of the intercostal nerves blocking dermatomes T2-T9. It provides long-acting analgesia on the anterolateral and posterior chest wall. This block has a very low potential for complications, such as pneumothorax and hematoma, and also provides more hemodynamic stability than a thoracic epidural (21). It has been used successfully for rib fractures and even for thoracotomies (25). A single shot provides sufficient analgesia for $6 \mathrm{~h}$ after a VATS, however, a continuous block can also be used (26).

Compared with the SAP block, the ESP block is performed more posteriorly, over the tip of the thoracic transverse process, and is intended to block both the intercostal nerves and the posterior rami of the spinal nerves from T3 to T9 (27). The duration of analgesia after a single injection ESP block is limited to $8 \mathrm{~h}$, however, it can be significantly prolonged by the addition of dexmedetomidine to the local anesthetic mixture or by threading a catheter (28). As with other plane blocks, there is a low probability of complications, including hemodynamic instability and pneumothorax, associated with this technique. ESP blocks are increasingly used for thoracic analgesia in VATS since they are relatively easy to execute (even for novices in regional anesthesia) and are performed far from vascular structures in a compressible site, superficial to the bony floor provided by the transverse process, instead of rib cage. These blocks have also shown to reduce intraand postoperative opioid consumption and the level of inflammatory cytokines in the postoperative period (29). The analgesic effect of an ESP block illustrated to be noninferior to that of a PVB, $24 \mathrm{~h}$ after VATS surgery. The ESP block also improves pain scores after breast, cardiac, thoracic, and abdominal surgeries (30).

In the context of VATS, it is still unclear which block, if any, is preferable, but both the SAP and the ESP block are very popular due to the good quality of analgesia and their ease of performance, although the ESP may provide superior analgesia (31-33).

Unlike epidurals, the ESP block can be performed preemptively or postoperatively, which can be highly beneficial in the event of unplanned thoracotomy, for example (34). Performing a plane block pre-emptively permits it to set in completely and prevents sensitization of the nociceptive system by blocking the surgical wound pain signals $(6,35)$. However, since the duration of the block is limited to
$8 \mathrm{~h}$, performing the block pre-emptively shortens the analgesic benefit of the block in the postoperative period, unless a catheter is threaded. In that case, a programmed intermittent bolus infusion mode, rather than a continuous mode, may provide better analgesia since the plane blocks work better with higher volumes of local anesthetics.

\section{Surgical infiltration}

Local anesthetic infiltration (LAI) of incision sites can be easily performed by the surgeon. Steps must be taken to avoid exceeding toxic doses, especially if a nerve block is also performed in conjunction with the anesthesiologist, in order to avoid potential neurologic and cardiac toxicity that can lead to fatal cardiac arrest. The recommended maximum dose of bupivacaine with epinephrine $(5 \mu \mathrm{g} / \mathrm{mL})$ is $175 \mathrm{mg}$, although many other factors affecting peak plasma concentration must be considered. Consulting with the anesthesiologist before performing LAI is highly recommended (36). When compared to the regional anesthesia techniques listed above, LAI of local anesthetics or liposomal bupivacaine appears to be an option solely for rescue analgesia when a block fails $(37,38)$. LAI cannot be recommended as a primary regional technique for analgesia in VATS.

\section{Part 2: multimodal analgesia}

Systemic opioids are still widely used in thoracic surgery. Some patients may have inadequate pain control despite using regional anesthesia. Indeed, failure of the technique, patient refusal or contraindication to regional anesthesia, are all examples where the use of opioids may become necessary. Additionally, post thoracotomy ISP can be significant even in the presence of a competent epidural analgesia (see Part 3: postoperative ISP in thoracic surgery) (39). Opioids are potent analgesics, however, their use is associated with significant side effects that can hinder and even prolong recovery, which is particularly why their use must be kept to a minimum or avoided entirely $(6,11,12,40)$. This can be achieved by using a multimodal analgesic protocol that combines many non-opioid analgesics initiated in the intraoperative period and continued, or not, in the postoperative period. A summary of the multimodal analgesic drugs is provided in Table 1.

Acetaminophen and non-steroidal anti-inflammatory drugs (NSAIDs) have opioid-sparing properties, especially when administered concomitantly, and should be administered regularly to all patients in the postoperative 
Table 1 Recommendations on the use, timing and dosage of multimodal nonopioid analgesic drugs for the management of postoperative pain after thoracic surgery

\begin{tabular}{|c|c|c|c|}
\hline Drug & Recommendation & Timing & Dosage \\
\hline Celecoxib & Routine use* & Preoperatively & $200 \mathrm{mg}$ bid \\
\hline Ketamine & $\begin{array}{l}\text { If regional analgesia impossible } \\
\text { Patient with chronic pain }\end{array}$ & Intraoperatively & $\begin{array}{l}0.15-0.25 \mathrm{mg} / \mathrm{kg} \text { iv bolus dose, can be } \\
\text { continued postoperatively }\end{array}$ \\
\hline Gabapentinoids & Not recommended & - & - \\
\hline Dexmedetomidine & Recommended & Intraoperatively & $0.5-1 \mu \mathrm{g} / \mathrm{kg}$ over $20 \mathrm{~min}$ \\
\hline Dexamethasone & Recommended & Intraoperatively & 4-8 mg IV \\
\hline
\end{tabular}

*, unless contra-indicated (e.g., advanced age, renal failure, hypovolemia, gastrointestinal bleeding). Bid, twice daily; IV, intravenous; qid, four times daily.

period, provided there are no contraindications (advanced age, renal failure, hypovolemia) (40). In addition, the preoperative administration of celecoxib, a selective NSAID, can be considered since it has shown to decrease postoperative pain and opioid requirements after major surgery (40). It does not alter platelet function, which is very interesting in the perioperative period, especially when the use of other anticoagulants for thromboprophylaxis are often used (41).

Compared to opioids alone, the addition of $\mathrm{N}$-methylD-aspartate (NMDA) Antagonist ketamine to morphine intravenous patient-controlled analgesia (IVPCA) significantly reduces consumption of the opioid and improves respiratory function after thoracotomy $(42,43)$. However, in the setting of TEA, supplemental benefits of ketamine are less clear. For example, one study found that ketamine could enhance analgesia in the early postoperative period and decrease the incidence of post-thoracotomy pain syndrome at 3 months after the surgery (44), however, this effect could not be replicated in three other studies $(42,45,46)$. Compared with thoracotomy, the analgesic effect of ketamine on postoperative pain after VATS has not been thoroughly evaluated. One study involving 70 VATS patients found that a fentanyl-based IVPCA with lowdose ketamine provided adequate postoperative analgesia, similar to that of a thoracic epidural, and with very few side effects (20). The analgesic benefit of ketamine has been very well demonstrated in a variety of surgical procedures (47). An initial bolus at induction of anesthesia, followed by an intraoperative infusion, can improve postoperative pain scores while reducing postoperative opioid consumption by $30-40 \%$. Ketamine should be considered for some patients, when regional anesthesia is not possible in the setting of thoracotomy or for patients on chronic opioid therapy (48).

Magnesium sulfate is also believed to have opioid sparing effects by blocking the NMDA receptor and central sensitization. Compared to IVPCA alone, magnesium sulfate reduced cumulative morphine consumption $48 \mathrm{~h}$ after thoracotomy in patients who had a contraindication to TEA or who refused it (49). However, it failed to provide further analgesic benefit in patients treated with TEA (50). In one study, patients undergoing VATS received an intraoperative infusion of magnesium sulfate, which reduced postoperative opioid requirements and improved postoperative pulmonary function tests (51). Like ketamine, the significant opioid-sparing effect and small analgesic effect of magnesium sulfate has been well demonstrated in various surgical settings. However, its effect in the presence of regional analgesia, or commonly used non-opioid analgesics, is less certain (52). Thus, magnesium sulfate could be considered in patients undergoing thoracotomy without regional analgesia and in whom the use of ketamine is not possible.

The impact of gabapentinoids on postoperative analgesia and the incidence of chronic postoperative pain has been studied extensively in various surgeries using different dosing protocols. In the setting of thoracotomy, gabapentin and pregabalin have no impact on the severity of acute pain 
at the surgical site, on the incidence or severity of ISP, or on the incidence of chronic postoperative pain (53-55). After VATS, one study found that a single preoperative dose of pregabalin $150 \mathrm{mg}$ reduced the severity of pain in the first $24 \mathrm{~h}$ (56). However, this analgesic effect could not be reproduced by another study despite using higher doses of pregabalin, nor could a beneficial effect on chronic pain be demonstrated (57). Also, there is very strong evidence demonstrating the lack of significant analgesic effect and the unfavorable side effect profile of gabapentinoids in the perioperative period. Thus, gabapentinoids should not be routinely used in the perioperative period (58).

Dexmedetomidine is a central alpha-2-agonist with sedative, analgesic and opioid-sparing properties (59). One study illustrated that a low-dose intravenous infusion of dexmedetomidine initiated before the end of surgery and continued for $12 \mathrm{~h}$ after thoracotomy amplified TEA (60). Patients receiving dexmedetomidine expressed lower Visual Analog Pain (VAS) scores during the first $48 \mathrm{~h}$ after surgery despite using fewer opioid analgesics. This analgesic and opioid-sparing effect of dexmedetomidine was also observed in patients undergoing VATS surgery. During the first $48 \mathrm{~h}$ after surgery, patients who received dexmedetomidine $1 \mu \mathrm{g} / \mathrm{kg}$ intraoperatively towards the end of their surgery experienced improved Quality of Recovery (QoR-40) scores, mostly relating to physical comfort and pain (61). Dexmedetomidine, added to the local anesthetic mixture, significantly prolongs the analgesic duration of regional blocks and reduces the total opioid consumption $48 \mathrm{~h}$ after VATS $(28,62)$. Additionally, this effect is further enhanced by the addition of perineural dexamethasone (62). Intraoperative dexmedetomidine also reduces the incidence of emergence agitation and cough after thoracic surgery, although, time to awakening from anesthesia may be prolonged and bradycardia may be observed $(60,61,63)$. Dexmedetomidine presents significant benefits in terms of analgesia and quality of recovery after thoracic surgery and its use should be considered.

Dexamethasone is an effective adjunct to multimodal analgesia strategies because it reduces postoperative pain, opioid consumption, and the incidence of postoperative nausea and vomiting in a general surgical setting (64). However, a single preoperative dose of $0.1 \mathrm{mg} / \mathrm{kg} \mathrm{did}$ not result in improved analgesia in patients undergoing thoracotomy and receiving TEA (65). This may be because the effect of dexamethasone is masked by a potent TEA, or by the low dose of dexamethasone that was used. Indeed, the analgesic effect of dexamethasone is dose-dependent, and doses $>0.1 \mathrm{mg} / \mathrm{kg}$ are more efficient (64). In patients undergoing VATS, the analgesic effect of intravenous dexamethasone has not been sufficiently evaluated. While it enhances the analgesic duration of regional blocks and reduces postoperative opioid requirements when it is added to the local anesthetic mixture used for regional blocks $(28,62,66)$, its effect may be less pronounced than that of perineural dexmedetomidine $(28,67)$. One study suggested that the perineural combination of these two adjuvants may lead to significantly further analgesic duration (62). However, considering that the intravenous administration of dexmedetomidine and dexamethasone provide similar prolongation of the analgesic duration of regional blocks while avoiding potential neurotoxicity associated with their perineural administration, their routine addition to the local anesthetic mixture for regional blocks cannot be recommended $(68,69)$.

Finally, lidocaine infusion during abdominal surgeries provides superior postoperative analgesia and reduces postoperative ileus (70). However, results in other surgeries are less evident, including VATS, where analgesic benefits could not be effectively demonstrated (71).

\section{Part 3: postoperative ISP in thoracic surgery}

The incidence of ISP is reported to be as high as $85 \%$ after thoracotomy and is usually of moderate to severe intensity. Though less frequently, it can also affect VATS patients (72). In the context of TEA, ISP can be the predominant source of pain and have a negative impact on postoperative recovery $(39,72)$. The pain is mostly located in the posterior part of the shoulder and begins as early as the first postoperative hour, however, gradually fading over the course of the first $3-4$ postoperative days $(72,74-77)$ and is very unlikely to become chronic (74).

ISP appears to originate most commonly from an irritation of the diaphragm and mediastinal pleura, and, to a lesser extent, from shoulder strain due to positioning during surgery $(39,78)$. TEA and opioids have a poor impact on the severity of ISP and multimodal interventions are often required to adequately treat and reduce its incidence $(73,75,76,79,80)$.

Effective treatments include the routine use of acetaminophen and NSAIDs $(74,77,79,81)$. Other drugs such as gabapentin and pregabalin have not proved to be beneficial $(53,82)$. Intraoperative phrenic nerve blocks, through local anesthetic infiltration of the diaphragmatic fat pad by the surgeon, are very efficient in reducing 
Table 2 Suggested multimodal analgesic combinations for the management of postoperative pain after thoracic surgery, depending on the context

\begin{tabular}{|c|c|c|c|}
\hline Intervention & Regional analgesia & Non opioid analgesics* & Opioids \\
\hline Planned & $\begin{array}{l}\text { TEA } 5 \mathrm{~mL} / \mathrm{h} \text { basal rate }+5 \mathrm{~mL} \text { bolus } \\
\text { (bupivacaine } 0.1 \% \text { with fentanyl } 2 \mu \mathrm{g} / \mathrm{mL} \text { ) }\end{array}$ & $\begin{array}{l}\text { Acetaminophen } \\
\text { Celecoxib } \\
\text { Dexamethasone }\end{array}$ & $\begin{array}{l}\text { PO doses may be needed for } \\
\text { ISP }\end{array}$ \\
\hline \multicolumn{4}{|l|}{ VATS } \\
\hline Routine & Single injection ESP block & $\begin{array}{l}\text { Acetaminophen } \\
\text { Celecoxib } \\
\text { Dexamethasone } \\
\text { Dexmedetomidine or ketamine }\end{array}$ & $\begin{array}{l}\text { PO doses usually sufficient } \\
\text { IVPCA may be needed }\end{array}$ \\
\hline $\begin{array}{l}\text { Severe OSA, high risk of } \\
\text { thoracotomy }\end{array}$ & $\begin{array}{l}\text { Strongly consider TEA } \\
\text { Continuous ESP block (with catheter) }\end{array}$ & $\begin{array}{l}\text { Acetaminophen } \\
\text { Celecoxib } \\
\text { Ketamine and/or dexmedetomidine } \\
\text { Dexamethasone }\end{array}$ & Avoid if severe OSA \\
\hline Chronic pain & As above & $\begin{array}{l}\text { Continue gabapentinoids if taken } \\
\text { preoperatively }\end{array}$ & $\begin{array}{l}\text { Higher doses of opioids may } \\
\text { be needed } \\
\text { Consider opioid + ketamine } \\
\text { IVPCA }\end{array}$ \\
\hline
\end{tabular}

*, refer to Table 1 for dosing. ESP, erector spinae plane block; IVPCA, intravenous patient-controlled analgesia; OSA, obstructive sleep apnea; PO, per os; TEA, thoracic epidural analgesia; VATS, video-assisted thoracic surgery.

the incidence and severity of ISP after both VATS and thoracotomy $(73,83-86)$. The analgesic duration of this block can be extended to $48 \mathrm{~h}$ with the use of long-acting local anesthetics, which are sufficient to provide analgesia when ISP is most severe, without significantly affecting postoperative respiratory function tests $(83,85,87)$. Stellate ganglion and interscalene brachial plexus blocks have also reduced the incidence and severity of ISP, most likely through blockade of the phrenic nerve, although their performance can be time and resource consuming (88-91). Studies evaluating the efficacy of suprascapular nerve and intrapleural blocks have not demonstrated a significant benefit in this regard $(87,92-95)$.

\section{Part 4: suggestions based on available literature and authors' experience (Table 2, Figure 2)}

In our institution, all patients scheduled for thoracic surgery receive a preoperative dose of acetaminophen $1 \mathrm{~g}$ and celecoxib $200 \mathrm{mg}$ (if not contraindicated). This drug protocol is continued into the postoperative period until the third postoperative day. A dose of dexamethasone 4-8 mg is also given after the induction of general anesthesia for postoperative pain and prevention of nausea and vomiting.

Unless contraindicated, all thoracotomy patients receive a TEA that is initiated before the surgical incision allowing a significant reduction in the use of intraoperative opioids. Postoperatively, patients will be kept on TEA until the second or third postoperative day, usually after removal of the chest tubes. Patients usually report excellent analgesia with the use of an epidural-based patient-controlled analgesia (PCA), which combines a low basal infusion rate to frequent bolus availability. Additionally, when such PCAs are used, hypotension is very uncommon. An intraoperative phrenic nerve block is usually not performed, and oral opioids are available as required to treat significant ISP. 
Planned thoracotomy

Preoperative

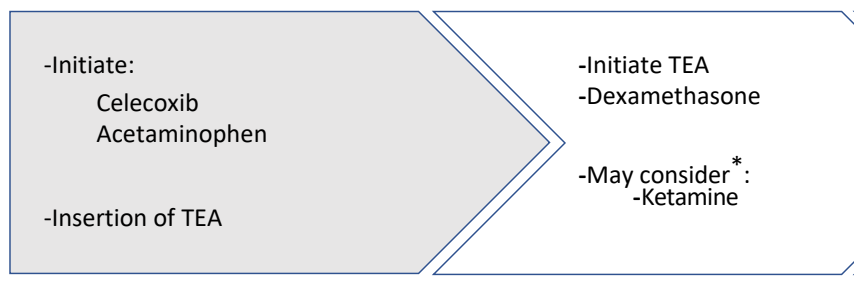

Planned VATS

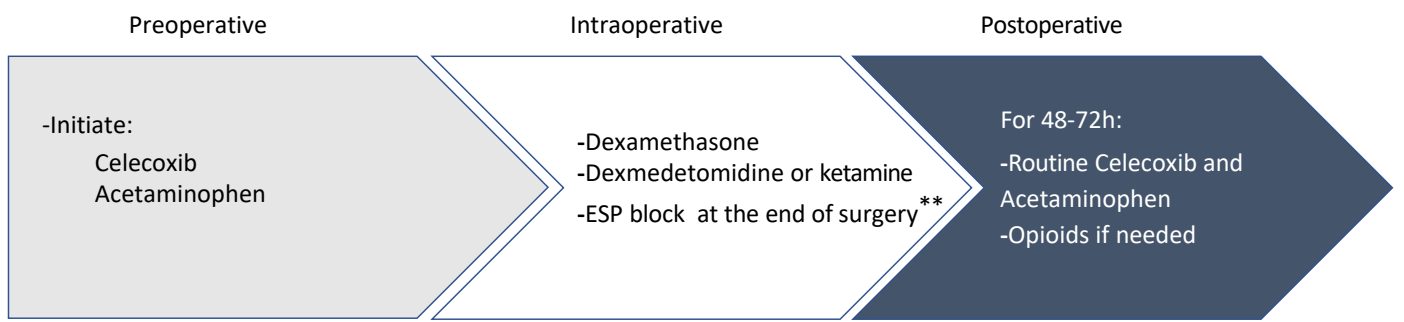

Figure 2 Timeline for the use of suggested regional blocks and multimodal analgesic drugs in thoracic surgery, according to surgery type. *, in the context of chronic pain or in the absence of TEA; **, consider continuous ESP block with catheter/TEA in the context of chronic pain, severe obstructive sleep apnea or very poor pulmonary function. TEA, thoracic epidural analgesia; PCA, patient-controlled analgesia; ESP, erector spinae plane.

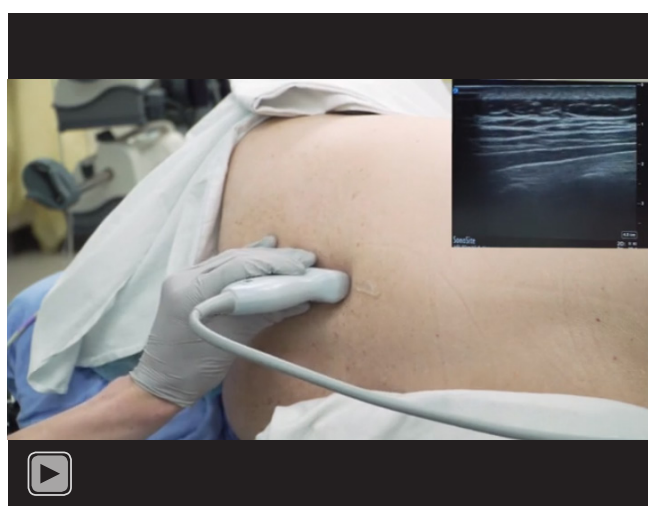

Video 1 Erector spinae plane block for minimally invasive thoracic surgery.

Patients who have a contraindication to or refuse TEA will usually receive an intraoperative bolus and infusion of ketamine along with a single-shot ESP block (if possible), followed postoperatively by an opioid and ketamine based IVPCA.

The analgesic strategy for VATS is more varied, reflecting the lack of consensus in the literature. Patients usually receive a single injection ESP block with $20 \mathrm{~mL}$
$0.5 \%$ ropivacaine that is usually performed after the end of surgery, before waking the patient (see Video 1: ESP block for minimally invasive thoracic surgery, digital content). TEA is only used in patients with poor pulmonary function, significant sleep apnea, or who are at high risk of conversion to open thoracotomy. Clear communication between surgeons and anesthesiologists on this specific risk is preoperatively warranted in our institution. An intraoperative bolus of ketamine or dexmedetomidine (see Table 1), depending on the anesthesiologist's preference, is quite often used, and the ketamine infusion is continued postoperatively only in patients with a history of chronic pain/opioid use. With the use of regional analgesic blocks, postoperative breakthrough pain is usually well managed with oral opioids, and opioid-based IVPCA is rarely needed. The occurrence of severe ISP after VATS is low, and an intraoperative phrenic nerve block is usually not performed. When significant, ISP is treated with oral opioids. Using this multimodal analgesic combination (acetaminophen, celecoxib, single injection ESP block, intraoperative bolus of dexmedetomidine or ketamine, and oral opioids), we find that postoperative pain is well managed, and most patients are discharged on postoperative day 2. In a few select cases, patients have even been discharged home on the morning 
after surgery, with the help of a continuous ESP block using an outpatient infusion pump.

\section{Limitations}

This review is limited by the heterogeneity and the relatively small number of clinical trials that assessed the analgesic benefits of the newer plane blocks and adjunct multimodal analgesic drugs, especially regarding minimally invasive surgery. Large scale studies evaluating the analgesic and fast-tracking benefits of combined regional and multimodal analgesic protocols are needed.

\section{Conclusions}

Unlike thoracotomy, the optimal analgesic protocol after minimally invasive thoracic surgery remains an open question. Various analgesic strategies have been evaluated in different settings, but none has been adopted as a clinical standard. Given the various generators of pain after thoracic surgery, a standardized analgesic strategy that combines multimodal to regional analgesia, while aiming at reducing parenteral opioids, appears to be necessary to provide proper postoperative analgesia and adequate recovery of lung function, although this has yet to be confirmed by large scale clinical trials.

\section{Acknowledgments}

Funding: The composition of this manuscript was supported by the Department of Anesthesiology of MaisonneuveRosemont Hospital/CIUSSS de l'Est de l'Ile de Montréal (CEMTL).

\section{Footnote}

Provenance and Peer Review: This article was commissioned by the Guest Editors (Jean Bussieres and George Rakovich) for the series "Recent Advances in Perioperative Care in Thoracic Surgery and Anesthesia" published in Current Challenges in Thoracic Surgery. The article has undergone external peer review.

Reporting Checklist: The authors have completed the Narrative Review reporting checklist. Available at https:// ccts.amegroups.com/article/view/10.21037/ccts-20-184/rc

Peer Review File: Available at https://ccts.amegroups.com/ article/view/10.21037/ccts-20-184/prf

Conflicts of Interest: All authors have completed the ICMJE uniform disclosure form (available at https://ccts. amegroups.com/article/view/10.21037/ccts-20-184/coif). The series "Recent Advances in Perioperative Care in Thoracic Surgery and Anesthesia" was commissioned by the editorial office without any funding or sponsorship. The authors have no other conflicts of interest to declare.

Ethical Statement: The authors are accountable for all aspects for the work in ensuring that questions related to the accuracy or integrity of any part of the work are appropriately investigated and resolved.

Open Access Statement: This is an Open Access article distributed in accordance with the Creative Commons Attribution-NonCommercial-NoDerivs 4.0 International License (CC BY-NC-ND 4.0), which permits the noncommercial replication and distribution of the article with the strict proviso that no changes or edits are made and the original work is properly cited (including links to both the formal publication through the relevant DOI and the license). See: https://creativecommons.org/licenses/by-nc-nd/4.0/.

\section{References}

1. Kaplowitz J, Papadakos PJ. Acute pain management for video-assisted thoracoscopic surgery: an update. J Cardiothorac Vasc Anesth 2012;26:312-21.

2. Bayman EO, Parekh KR, Keech J, et al. A Prospective Study of Chronic Pain after Thoracic Surgery. Anesthesiology 2017;126:938-51.

3. Nagahiro I, Andou A, Aoe M, et al. Pulmonary function, postoperative pain, and serum cytokine level after lobectomy: a comparison of VATS and conventional procedure. Ann Thorac Surg 2001;72:362-5.

4. Schug SA, Lavand'homme P, Barke A, et al. The IASP classification of chronic pain for ICD-11: chronic postsurgical or posttraumatic pain. Pain 2019;160:45-52.

5. Gureje O, Von Korff M, Simon GE, et al. Persistent pain and well-being: a World Health Organization Study in Primary Care. JAMA 1998;280:147-51.

6. Richebé P, Capdevila X, Rivat C. Persistent Postsurgical Pain: Pathophysiology and Preventative Pharmacologic Considerations. Anesthesiology 2018;129:590-607.

7. Wildgaard K, Ravn J, Kehlet H. Chronic postthoracotomy pain: a critical review of pathogenic 
mechanisms and strategies for prevention. Eur J

Cardiothorac Surg 2009;36:170-80.

8. Grosen K, Laue Petersen G, Pfeiffer-Jensen M, et al. Persistent post-surgical pain following anterior thoracotomy for lung cancer: a cross-sectional study of prevalence, characteristics and interference with functioning. Eur J Cardiothorac Surg 2013;43:95-103.

9. Katz J, Seltzer Z. Transition from acute to chronic postsurgical pain: risk factors and protective factors. Expert Rev Neurother 2009;9:723-44.

10. Geil D, Thomas C, Zimmer A, et al. Chronified Pain Following Operative Procedures. Dtsch Arztebl Int 2019;116:261-6.

11. Gustafsson UO, Scott MJ, Schwenk W, et al. Guidelines for perioperative care in elective colonic surgery: Enhanced Recovery After Surgery (ERAS(®)) Society recommendations. World J Surg 2013;37:259-84.

12. Oderda GM, Evans RS, Lloyd J, et al. Cost of opioidrelated adverse drug events in surgical patients. J Pain Symptom Manage 2003;25:276-83.

13. Bialka S, Copik M, Daszkiewicz A, et al. Comparison of different methods of postoperative analgesia after thoracotomy-a randomized controlled trial. J Thorac Dis 2018;10:4874-82.

14. Wu CL, Cohen SR, Richman JM, et al. Efficacy of postoperative patient-controlled and continuous infusion epidural analgesia versus intravenous patient-controlled analgesia with opioids: a meta-analysis. Anesthesiology 2005;103:1079-88; quiz 1109-10.

15. Sentürk M, Ozcan PE, Talu GK, et al. The effects of three different analgesia techniques on long-term postthoracotomy pain. Anesth Analg 2002;94:11-5, table of contents.

16. Salengros JC, Huybrechts I, Ducart A, et al. Different anesthetic techniques associated with different incidences of chronic post-thoracotomy pain: low-dose remifentanil plus presurgical epidural analgesia is preferable to highdose remifentanil with postsurgical epidural analgesia. J Cardiothorac Vasc Anesth 2010;24:608-16.

17. Yeung JH, Gates S, Naidu BV, et al. Paravertebral block versus thoracic epidural for patients undergoing thoracotomy. Cochrane Database Syst Rev 2016;2:CD009121.

18. Haager B, Schmid D, Eschbach J, et al. Regional versus systemic analgesia in video-assisted thoracoscopic lobectomy: a retrospective analysis. BMC Anesthesiol 2019; $19: 183$

19. Steinthorsdottir KJ, Wildgaard L, Hansen HJ, et al.
Regional analgesia for video-assisted thoracic surgery: a systematic review. Eur J Cardiothorac Surg 2014;45:959-66.

20. Tseng WC, Lin WL, Lai HC, et al. Fentanyl-based intravenous patient-controlled analgesia with low dose of ketamine is not inferior to thoracic epidural analgesia for acute post-thoracotomy pain following video-assisted thoracic surgery: A randomized controlled study. Medicine (Baltimore) 2019;98:e16403.

21. Alzahrani T. Pain relief following thoracic surgical procedures: A literature review of the uncommon techniques. Saudi J Anaesth 2017;11:327-31.

22. Seidel R, Wree A, Schulze M. Thoracic-paravertebral blocks: comparative anatomical study with different injection techniques and volumes. Reg Anesth Pain Med 2020;45:102-6.

23. Pace MM, Sharma B, Anderson-Dam J, et al. UltrasoundGuided Thoracic Paravertebral Blockade: A Retrospective Study of the Incidence of Complications. Anesth Analg 2016;122:1186-91.

24. Taketa Y, Irisawa Y, Fujitani T. Comparison of ultrasoundguided erector spinae plane block and thoracic paravertebral block for postoperative analgesia after videoassisted thoracic surgery: a randomized controlled noninferiority clinical trial. Reg Anesth Pain Med 2019. [Epub ahead of print]. doi: 10.1136/rapm-2019-100827.

25. Umari M, Falini S, Segat M, et al. Anesthesia and fasttrack in video-assisted thoracic surgery (VATS): from evidence to practice. J Thorac Dis 2018;10:S542-54.

26. Ökmen K, Ökmen BM. The efficacy of serratus anterior plane block in analgesia for thoracotomy: a retrospective study. J Anesth 2017;31:579-85.

27. Forero M, Adhikary SD, Lopez H, et al. The Erector Spinae Plane Block: A Novel Analgesic Technique in Thoracic Neuropathic Pain. Reg Anesth Pain Med 2016;41:621-7.

28. Gao Z, Xiao Y, Wang Q, et al. Comparison of dexmedetomidine and dexamethasone as adjuvant for ropivacaine in ultrasound-guided erector spinae plane block for video-assisted thoracoscopic lobectomy surgery: a randomized, double-blind, placebo-controlled trial. Ann Transl Med 2019;7:668.

29. Liu L, Ni XX, Zhang LW, et al. Effects of ultrasoundguided erector spinae plane block on postoperative analgesia and plasma cytokine levels after uniportal VATS: a prospective randomized controlled trial. J Anesth 2021;35:3-9.

30. Kot P, Rodriguez P, Granell M, et al. The erector spinae plane block: a narrative review. Korean J Anesthesiol 
2019;72:209-20.

31. Chen N, Qiao Q, Chen R, et al. The effect of ultrasoundguided intercostal nerve block, single-injection erector spinae plane block and multiple-injection paravertebral block on postoperative analgesia in thoracoscopic surgery: A randomized, double-blinded, clinical trial. J Clin Anesth 2020;59:106-11.

32. Zhao H, Xin L, Feng Y. The effect of preoperative erector spinae plane vs. paravertebral blocks on patientcontrolled oxycodone consumption after video-assisted thoracic surgery: A prospective randomized, blinded, noninferiority study. J Clin Anesth 2020;62:109737.

33. Finnerty DT, McMahon A, McNamara JR, et al. Comparing erector spinae plane block with serratus anterior plane block for minimally invasive thoracic surgery: a randomised clinical trial. Br J Anaesth 2020;125:802-10.

34. Raft J, Chin KJ, Belanger ME, et al. Continuous Erector Spinae Plane Block for thoracotomy analgesia after epidural failure. J Clin Anesth 2019;54:132-3.

35. Dahl JB, Møiniche S. Pre-emptive analgesia. Br Med Bull 2004;71:13-27.

36. Rosenberg PH, Veering BT, Urmey WF. Maximum recommended doses of local anesthetics: a multifactorial concept. Reg Anesth Pain Med 2004;29:564-24.

37. Sztain JF, Gabriel RA, Said ET. Thoracic Epidurals are Associated With Decreased Opioid Consumption Compared to Surgical Infiltration of Liposomal Bupivacaine Following Video-Assisted Thoracoscopic Surgery for Lobectomy: A Retrospective Cohort Analysis. J Cardiothorac Vasc Anesth 2019;33:694-8.

38. Chen G, Li Y, Zhang Y, et al. Effects of serratus anterior plane block for postoperative analgesia after thoracoscopic surgery compared with local anesthetic infiltration: a randomized clinical trial. J Pain Res 2019;12:2411-7.

39. Yousefshahi F, Predescu O, Colizza M, et al. Postthoracotomy Ipsilateral Shoulder Pain: A Literature Review on Characteristics and Treatment. Pain Res Manag 2016;2016:3652726.

40. Chou R, Gordon DB, de Leon-Casasola OA, et al. Management of Postoperative Pain: A Clinical Practice Guideline From the American Pain Society, the American Society of Regional Anesthesia and Pain Medicine, and the American Society of Anesthesiologists' Committee on Regional Anesthesia, Executive Committee, and Administrative Council. J Pain 2016;17:131-57.

41. Leese PT, Hubbard RC, Karim A, et al. Effects of celecoxib, a novel cyclooxygenase-2 inhibitor, on platelet function in healthy adults: a randomized, controlled trial. J Clin Pharmacol 2000;40:124-32.

42. Dualé C, Sibaud F, Guastella V, et al. Perioperative ketamine does not prevent chronic pain after thoracotomy. Eur J Pain 2009;13:497-505.

43. Michelet P, Guervilly C, Hélaine A, et al. Adding ketamine to morphine for patient-controlled analgesia after thoracic surgery: influence on morphine consumption, respiratory function, and nocturnal desaturation. Br J Anaesth 2007;99:396-403.

44. Suzuki M, Haraguti S, Sugimoto K, et al. Low-dose intravenous ketamine potentiates epidural analgesia after thoracotomy. Anesthesiology 2006;105:111-9.

45. Joseph C, Gaillat F, Duponq R, et al. Is there any benefit to adding intravenous ketamine to patientcontrolled epidural analgesia after thoracic surgery? A randomized double-blind study. Eur J Cardiothorac Surg 2012;42:e58-65.

46. Mendola C, Cammarota G, Netto R, et al. S(+)-ketamine for control of perioperative pain and prevention of post thoracotomy pain syndrome: a randomized, double-blind study. Minerva Anestesiol 2012;78:757-66.

47. Jouguelet-Lacoste J, La Colla L, Schilling D, et al. The use of intravenous infusion or single dose of low-dose ketamine for postoperative analgesia: a review of the current literature. Pain Med 2015;16:383-403.

48. Gharaei B, Jafari A, Aghamohammadi H, et al. Opioidsparing effect of preemptive bolus low-dose ketamine for moderate sedation in opioid abusers undergoing extracorporeal shock wave lithotripsy: a randomized clinical trial. Anesth Analg 2013;116:75-80.

49. Ozcan PE, Tugrul S, Senturk NM, et al. Role of magnesium sulfate in postoperative pain management for patients undergoing thoracotomy. J Cardiothorac Vasc Anesth 2007;21:827-31.

50. Kogler J. The analgesic effect of magnesium sulfate in patients undergoing thoracotomy. Acta Clin Croat 2009;48:19-26.

51. Sohn HM, Jheon SH, Nam S, et al. Magnesium sulphate improves pulmonary function after videoassisted thoracoscopic surgery: A randomised doubleblind placebo-controlled study. Eur J Anaesthesiol 2017;34:508-14.

52. Albrecht E, Kirkham KR, Liu SS, et al. Peri-operative intravenous administration of magnesium sulphate and postoperative pain: a meta-analysis. Anaesthesia 2013;68:79-90.

53. Huot MP, Chouinard P, Girard F, et al. Gabapentin does 
not reduce post-thoracotomy shoulder pain: a randomized, double-blind placebo-controlled study. Can J Anaesth 2008;55:337-43.

54. Brulotte V, Ruel MM, Lafontaine E, et al. Impact of pregabalin on the occurrence of postthoracotomy pain syndrome: a randomized trial. Reg Anesth Pain Med 2015;40:262-9.

55. Grosen K, Drewes AM, Højsgaard A, et al. Perioperative gabapentin for the prevention of persistent pain after thoracotomy: a randomized controlled trial. Eur J Cardiothorac Surg 2014;46:76-85.

56. Kim JC, Byun S, Kim S, et al. Effect of preoperative pregabalin as an adjunct to a multimodal analgesic regimen in video-assisted thoracoscopic surgery: A randomized controlled trial. Medicine (Baltimore) 2017;96:e8644.

57. Konstantatos AH, Howard W, Story D, et al. A randomised controlled trial of peri-operative pregabalin vs. placebo for video-assisted thoracoscopic surgery. Anaesthesia 2016;71:192-7.

58. Verret M, Lauzier F, Zarychanski R, et al. Perioperative Use of Gabapentinoids for the Management of Postoperative Acute Pain: A Systematic Review and Metaanalysis. Anesthesiology 2020;133:265-79.

59. Blaudszun G, Lysakowski C, Elia N, et al. Effect of perioperative systemic $\alpha 2$ agonists on postoperative morphine consumption and pain intensity: systematic review and meta-analysis of randomized controlled trials. Anesthesiology 2012;116:1312-22.

60. Choi EJ, Yoon JP, Choi YM, et al. Intravenous infusion of dexmedetomidine amplifies thoracic epidural analgesic effect after open thoracotomy: A prospective, doubleblind, randomized controlled trial. Medicine (Baltimore) 2019;98:e17983.

61. Lee SH, Lee CY, Lee JG, et al. Intraoperative Dexmedetomidine Improves the Quality of Recovery and Postoperative Pulmonary Function in Patients Undergoing Video-assisted Thoracoscopic Surgery: A CONSORTProspective, Randomized, Controlled Trial. Medicine (Baltimore) 2016;95:e2854.

62. Zhang P, Liu S, Zhu J, et al. Dexamethasone and dexmedetomidine as adjuvants to local anesthetic mixture in intercostal nerve block for thoracoscopic pneumonectomy: a prospective randomized study. Reg Anesth Pain Med 2019. [Epub ahead of print]. doi: 10.1136/rapm-2018-100221.

63. Kim JA, Ahn HJ, Yang M, et al. Intraoperative use of dexmedetomidine for the prevention of emergence agitation and postoperative delirium in thoracic surgery: a randomized-controlled trial. Can J Anaesth 2019;66:371-9.

64. De Oliveira GS Jr, Almeida MD, Benzon HT, et al. Perioperative single dose systemic dexamethasone for postoperative pain: a meta-analysis of randomized controlled trials. Anesthesiology 2011;115:575-88.

65. Joung KW, Kim HR, Kim WJ, et al. Preoperative dexamethasone for acute post-thoracotomy analgesia: a randomized, double-blind, placebo-controlled study. BMC Anesthesiol 2018;18:135.

66. Mao Y, Zuo Y, Mei B, et al. Efficacy of perineural dexamethasone with ropivacaine in thoracic paravertebral block for postoperative analgesia in elective thoracotomy: a randomized, double-blind, placebo-controlled trial. J Pain Res 2018;11:1811-9.

67. Aliste J, Layera S, Bravo D, et al. Randomized comparison between perineural dexamethasone and dexmedetomidine for ultrasound-guided infraclavicular block. Reg Anesth Pain Med 2019. [Epub ahead of print]. doi: 10.1136/rapm2019-100680.

68. Yu ZY, Geng J, Li ZQ, et al. Dexmedetomidine enhances ropivacaine-induced sciatic nerve injury in diabetic rats. $\mathrm{Br}$ J Anaesth 2019;122:141-9.

69. Pehora C, Pearson AM, Kaushal A, et al. Dexamethasone as an adjuvant to peripheral nerve block. Cochrane Database Syst Rev 2017;11:CD011770.

70. Vigneault L, Turgeon AF, Côté D, et al. Perioperative intravenous lidocaine infusion for postoperative pain control: a meta-analysis of randomized controlled trials. Can J Anaesth 2011;58:22-37.

71. Slovack M, Taylor B, Bryce R, et al. Does intravenous lidocaine infusion during video-assisted thoracoscopic surgery reduce postoperative analgesia? A randomized controlled study. Can J Anaesth 2015;62:676-7.

72. Bunchungmongkol N, Pipanmekaporn T, Paiboonworachat $\mathrm{S}$, et al. Incidence and risk factors associated with ipsilateral shoulder pain after thoracic surgery. J Cardiothorac Vasc Anesth 2014;28:979-82.

73. Scawn ND, Pennefather SH, Soorae A, et al. Ipsilateral shoulder pain after thoracotomy with epidural analgesia: the influence of phrenic nerve infiltration with lidocaine. Anesth Analg 2001;93:260-4, 1st contents page.

74. Blichfeldt-Eckhardt MR, Andersen C, Ørding H, et al. Shoulder Pain After Thoracic Surgery: Type and Time Course, a Prospective Cohort Study. J Cardiothorac Vasc Anesth 2017;31:147-51.

75. Mac TB, Girard F, Chouinard P, et al. Acetaminophen decreases early post-thoracotomy ipsilateral shoulder pain in patients with thoracic epidural analgesia: a double-blind 
placebo-controlled study. J Cardiothorac Vasc Anesth 2005;19:475-8.

76. MacDougall P. Postthoracotomy shoulder pain: diagnosis and management. Curr Opin Anaesthesiol 2008;21:12-5.

77. Pipanmekaporn T, Punjasawadwong Y, Charuluxananan $\mathrm{S}$, et al. The Effectiveness of Intravenous Parecoxib on the Incidence of Ipsilateral Shoulder Pain After Thoracotomy: A Randomized, Double-Blind, Placebo-Controlled Trial. J Cardiothorac Vasc Anesth 2018;32:302-8.

78. Blichfeldt-Eckhardt MR, Toft P. Treatment of ipsilateral shoulder pain after thoracic surgery-time for comparative studies? J Thorac Dis 2019;11:S417-9.

79. Barak M, Ziser A, Katz Y. Thoracic epidural local anesthetics are ineffective in alleviating post-thoracotomy ipsilateral shoulder pain. J Cardiothorac Vasc Anesth 2004;18:458-60.

80. MacDougall P, Slinger P. Post-thoracotomy shoulder pain and gabapentin: a tale of two enigmas. Can J Anaesth 2008;55:323-7.

81. Burgess FW, Anderson DM, Colonna D, et al. Ipsilateral shoulder pain following thoracic surgery. Anesthesiology 1993;78:365-8.

82. Imai Y, Imai K, Kimura T, et al. Evaluation of postoperative pregabalin for attenuation of postoperative shoulder pain after thoracotomy in patients with lung cancer, a preliminary result. Gen Thorac Cardiovasc Surg 2015;63:99-104.

83. Danelli G, Berti M, Casati A, et al. Ipsilateral shoulder pain after thoracotomy surgery: a prospective, randomized, double-blind, placebo-controlled evaluation of the efficacy of infiltrating the phrenic nerve with $0.2 \% \mathrm{wt} / \mathrm{vol}$ ropivacaine. Eur J Anaesthesiol 2007;24:596-601.

84. Hodge A, Rapchuk IL, Gurunathan U. Postoperative Pain Management and the Incidence of Ipsilateral Shoulder Pain After Thoracic Surgery at an Australian Tertiary-Care Hospital: A Prospective Audit. J Cardiothorac Vasc Anesth 2021;35:555-62.

85. Manzoor S, Khan T, Zahoor SA, et al. Post-thoracotomy ipsilateral shoulder pain: What should be preferred to optimize it - phrenic nerve infiltration or paracetamol infusion? Ann Card Anaesth 2019;22:291-6.

86. Martinez-Barenys C, Busquets J, de Castro PE, et al. Randomized double-blind comparison of phrenic nerve infiltration and suprascapular nerve block for ipsilateral shoulder pain after thoracic surgery. Eur J Cardiothorac
Surg 2011;40:106-12.

87. Elfokery BM, Tawfic SA, Abdelrahman AM, et al. Comparative study on the analgesic effect of acute ipsilateral shoulder pain after open thoracotomy between preoperative ultrasound guided suprascapular nerve block (SNB) and intraoperative phrenic nerve infiltration (PNI) in cancer lung patients. J Egypt Natl Canc Inst 2018;30:27-31.

88. Barak M, Iaroshevski D, Poppa E, et al. Low-volume interscalene brachial plexus block for post-thoracotomy shoulder pain. J Cardiothorac Vasc Anesth 2007;21:554-7.

89. Garner L, Coats RR. Ipsilateral stellate ganglion block effective for treating shoulder pain after thoracotomy. Anesth Analg 1994;78:1195-6.

90. Ng KP, Chow YF. Brachial plexus block for ipsilateral shoulder pain after thoracotomy. Anaesth Intensive Care 1997;25:74-6.

91. Woo JH, Kim YJ, Kim KC, et al. The effect of interscalene block on ipsilateral shoulder pain and pulmonary function in patients undergoing lung lobectomy: A randomized controlled trial. Medicine (Baltimore) 2018;97:e11034.

92. Ozyuvaci E, Akyol O, Sitilci T, et al. Preoperatıve ultrasound-guided suprascapular nerve block for postthoracotomy shoulder pain. Curr Ther Res Clin Exp 2013;74:44-8

93. Pennefather SH, Akrofi ME, Kendall JB, et al. Doubleblind comparison of intrapleural saline and $0.25 \%$ bupivacaine for ipsilateral shoulder pain after thoracotomy in patients receiving thoracic epidural analgesia. $\mathrm{Br} \mathrm{J}$ Anaesth 2005;94:234-8.

94. Saha S, Brish EL, Lowry AM, et al. In select patients, ipsilateral post-thoracotomy shoulder pain relieved by suprascapular nerve block. Am J Ther 2011;18:309-12.

95. Tan N, Agnew NM, Scawn ND, et al. Suprascapular nerve block for ipsilateral shoulder pain after thoracotomy with thoracic epidural analgesia: a double-blind comparison of $0.5 \%$ bupivacaine and $0.9 \%$ saline. Anesth Analg 2002;94:199-202, table of contents.

doi: $10.21037 /$ ccts-20-184

Cite this article as: Clairoux A, Issa R, Bélanger MÈ, Urbanowicz R, Richebé P, Brulotte V. Perioperative pain management for thoracic surgery: a narrative review of the literature. Curr Chall Thorac Surg 2021. 